\title{
Virgin River multi-objective optimization: maximizing endangered fish habitat and minimizing costs
}

\author{
Leon Basdekas, Luis A. Bastidas, Thomas B. Hardy, Arthur J. Caplan \& Mac \\ McKee
}

To cite this article: Leon Basdekas, Luis A. Bastidas, Thomas B. Hardy, Arthur J. Caplan \& Mac McKee (2014) Virgin River multi-objective optimization: maximizing endangered fish habitat and minimizing costs, International Journal of River Basin Management, 12:1, 15-28, DOI: 10.1080/15715124.2013.879592

To link to this article: http://dx.doi.org/10.1080/15715124.2013.879592

Published online: 21 Feb 2014.

Submit your article to this journal $₫$

Lll Article views: 95

Q View related articles $\asymp$

View Crossmark data $\nearrow$

Citing articles: 1 View citing articles $₫$ 


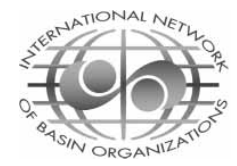

\title{
Virgin River multi-objective optimization: maximizing endangered fish habitat and minimizing costs
}

\author{
LEON BASDEKAS, Research Engineer, PhD Student, Department of Civil and Environmental Engineering and \\ Utah Water Research Laboratory, Utah State University, 8200 Old Main Hill, Logan, UT 84322-8200, USA. Email: \\ basdekas@gmail.com (authorfor correspondence)
}

LUIS A. BASTIDAS, Associate Professor, Department of Civil and Environmental Engineering and Utah Water Research Laboratory, Utah State University, 8200 Old Main Hill, Logan, UT 84322-8200, USA. Email: lucho.bastidas@gmail.com

THOMAS B. HARDY, Professor, Department of Civil and Environmental Engineering and Utah Water Research Laboratory, Utah State University, 8200 Old Main Hill, Logan, UT 84322-8200, USA. Email: thom.hardy@txstate.edu

ARTHUR J. CAPLAN, Professor, Department of Civil and Environmental Engineering and Utah Water Research Laboratory, Utah State University, 8200 Old Main Hill, Logan, UT 84322-8200, USA. Email: arthur.caplan@usu.edu

MAC MCKEE, Professor, Department of Civil and Environmental Engineering and Utah Water Research

Laboratory, Utah State University, 8200 Old Main Hill, Logan, UT 84322-8200, USA. Email: mac.mckee@usu.edu

\begin{abstract}
This paper discusses a comparative analysis of hypothetical operational scenarios by the use of dynamic temperature and fish habitat modelling in a multi-objective framework in the Virgin River Basin, Utah. Results were compared on the basis of quantified fish habitat, operational costs, and hydropower revenue. The modelling framework, the Virgin River Operation Optimization Model, is considered as a basin-level planning model. The optimization objectives were to minimize net river system operational cost of the Washington County Water Conservation District and maximize endangered fish habitat. Considerations included infrastructure alternatives to increase flow and cold water discharges as well as demand reductions. Given the nature of the problem, an optimization procedure was developed to approximate a Pareto front or trade-off surface for the two management objectives. This trade-off surface approximation is desired to help users compare the merits of any particular solution. The relative differences between alternatives elucidated sensitivities to the system responses along the approximated Pareto front. Limitations to the methods are discussed and recommendations for future work are provided.
\end{abstract}

Keywords: Multi-objective optimization; fish habitat; operational costs; river management; stream temperature; endangered species

\section{Introduction}

The study area, which lies within the Virgin River Basin located in Southwestern Utah, is host to fish species listed under the Endangered Species Act as either threatened or endangered of extinction which include the woundfin minnow (Plagopterus argentissimus) (USDI 1970) and Virgin River chub (Gila robusta seminuda) (USDI 1989). Other native fish species such as the Virgin spinedace (Lepidomeda mollispinis mollispinis) flannelmouth sucker (Catostomus latipinnis), the desert sucker (Catostomus clarki), and Speckeld dace (Rhynichthys osculus) have experienced less severe declines (UDNR 2002). The decline of these Virgin River native fishes has been attributed to the cumulative impacts of competition from nonnative fish species (Addley et al. 2005), and alterations to the natural flow, temperature, and sediment regimes (USDI 2000).

As a result of human activities and subsequent listing of fish species, water resources studies have been conducted to better understand the problems and find solutions to these challenging interdisciplinary problems. Ward and Booker (2003) discuss their application of a General Algebraic Modelling System model to the Rio Grande River Basin. They tested different

Received 9 May 2013. Accepted 20 November 2013.

ISSN 1571-5124 print/ISSN 1814-2060 online http://dx.doi.org/10.1080/15715124.2013.879592 
options examining the benefits and costs associated with the instream flow requirement while meeting interstate and international treaty requirements and demand from agriculture and municipal and industrial (M\&I) uses. The study examined 44 years at an annual time step with the objective of maximizing beneficial use, which requires diversions for agriculture and M\&I, while meeting system constraints and tracking economic impacts. An annual time step certainly required simplifying assumptions for both man-made and natural system representations. Campbell et al. (2001) describe comparisons of water management alternatives in the Klamath River Basin in Oregon and California using the system impact assessment model (SIAM) modelling system. Part of the SIAM modelling system includes an existing water mass balance model and a water quality/temperature model (HEC-5Q) to simulate various alternatives. Biological criteria evaluated were average daily acute and chronic temperatures as well as dissolved oxygen for salmonid species. The study evaluated specific alternatives but agriculture needs and river operations were not optimized.

Cardwell et al. (1996) describe building a multi-objective linear programming model to optimize a temperature modified Weighted Usable Area (WUA) (i.e. fish habitat) at a monthly time step. The objectives of flow optimization and fish habitat maximization were incorporated into a single weighted objective function. Using a proposed habitat capacity metric utilizing WUA, the authors demonstrated the utility of a planning-level optimization tool similar to what is proposed for this study; however, water temperature was not modelled dynamically. They recommend more detailed modelling after a range of suitable alternatives are chosen.

Bishop et al. (1990) describe using the modular in-core nonlinear optimization system (MINOS) to optimize existing and future hydropower revenue while maximizing fish habitat. Decision variables were penstock diameters and the monthly flow rates for the hydropower plant alternative configurations. The Physical Habitat Simulation System was used as part of the instream flow incremental methodology framework to develop a functional relationship between flow and instream flow benefits. A trade-off was defined and suggested for the use in negotiations for instream flow requirements in the hydropower plant re-licensing process. While this study developed an optimization framework to consider system operations, it used functional relationships for habitat rather than dynamic stream temperature modelling on a sub-daily time step and subsequent habitat estimates.

In order to meet water demands for municipal, industrial, hydropower, and limited agriculture, the water resources of the study area within the Virgin River Basin must be operated in an optimal manner to meet the requisite demands for beneficial out-of-stream uses while meeting environmental flow and temperature targets defined by species recovery efforts within the basin. To assist with assessing these competing objectives, a modelling framework was developed that would allow resource managers to evaluate different management options including new infrastructure and/or target environmental flows.

Basdekas (2007) describes work in four major areas of model development used for this study: a temperature model, input data needs and subsequent validation, development of a new fish habitat metric, and the integration of these modelling components into an operations model. Performing dynamic deterministic modelling of maximum daily water temperatures was a critical element for fish habitat modelling. We demonstrate the use of this modelling framework as a tool that allows for the pragmatic trade-off evaluation of water resource operation and/or infrastructure alternatives at a basin-wide planning level.

In multi-objective analysis, the Pareto optimum concept, also known as a noninferior solution is used. Qualitatively, a Pareto solution of a multi-objective problem does not, in general, have a unique solution. It is not usually possible to find a single point at which all the criteria have their minima. Instead, it is common to have a set of solutions, with the property that moving from one solution to another results in the improvement of one criterion while causing deterioration in another. This surface is called the Pareto set. In the present case, of a natural system, the Pareto set is unknown, and we use a search algorithm to finds points in a so-called 'Pareto front' which is an approximation of the actual Pareto set.

The concept of Pareto optimality was used to allow a user to evaluate a trade-off surface resulting from different operational options. This type of Pareto front result will allow a user to determine the merit of each of the individual solutions along the Pareto front. In this study, we approximate the Pareto front for four scenarios and the term Pareto front is used in the context of an approximated front throughout this manuscript. Without the multi-objective optimization approach, it is less likely that an optimal trade-off could be found and likely lie in an inferior decision space.

\section{Methods}

Evolutionary algorithms (EAs) are a common method for optimization of nonlinear problems due to their ability to find near optimal solutions while not requiring knowledge of the local gradient. Ritzel et al. (1994) describe using an EA to solve multi-objective groundwater pollution problems. They discuss a conceptual method where one objective is explored while the other remains constrained at a constant. Through many model runs, changing the constrained objective will produce a trade-off 
front. Gupta et al. (1998) also describe the process of multiobjective optimization using single objective optimization and weighting of the objective functions where the sum of weights is equal to one. They consider this to be an expensive proposition in terms of computational time requirements due to the need to solve a single objective optimization problem for each Pareto solution.

In order to gain a sense of the Pareto front, 5000 Monte Carlo simulations were performed. Randomly selecting decision variables, running simulations, and calculating the corresponding objective functions accomplished this. The results suggested that the responses, to various scenarios, would generally produce a Pareto front with little trade-off in objectives. It was decided that the use of a multi-objective optimization algorithm would encounter difficulties with resolving differences given the steep Pareto front and the known tendency of many such algorithms towards clustering the solutions (Das and Dennis 1998). Therefore, it was decided to use a weighting procedure similar to that described by Gupta et al. (1998).

Each of the two objectives was percentage weighted, one for net cost and the other for dynamically modelled thermal habitat at $0 / 100,25 / 75,50 / 50,75 / 25,100 / 0$ and thus an estimate of the Pareto front was made using a global optimization algorithm. Note that each of the weighting combinations sum to one, e.g. the $25 / 75$ weighting scheme is developed by applying a 0.25 weight multiplied by the value for objective function one and applying a 0.75 weight multiplied by the value for objective function two. We recognize the limitations of approximating a Pareto front with so few points; however, this would allow us to proceed with a proof of concept. For this study, we used the Shuffled Complex Evolution (SCE) algorithm (Duan et al. 1992) which was readily available at the time of the work completion.

SCE is a mixed type EA where complexes (groups of decision variables) are assembled, shuffled, and evolved towards a solution. SCE uses an adaptive search technique starting with a population of points that has been sampled randomly. The population is partitioned into communities each containing $2 n+1$ points, in this study $n=5$, the dimensionality of the problem. Each community has a subcomplex randomly selected from it and each is evolved separately using a simplex to search in the direction of improvement. During the simplex search process, mutation and replacement are used and the results reinserted back into the community where the communities are then sorted and shuffled allowing information to be shared. The process is repeated a number of times, as specified by the user. The population then tends to converge to an area of a global optimum, here a weighted run for each point along the Pareto front.

\section{Background}

The study area lies within Virgin River Basin and Washington County in Southwestern Utah, and is characterized by hot dry summers and mild winters (Figure 1). Mean annual flow for the Virgin River measured at Virgin, Utah is $4.9 \mathrm{~cm}$ (174 cfs) with a maximum of $14.9 \mathrm{~cm}$ (526 cfs) over an 86-year period of record (USGS 2003). Summer thunderstorm events

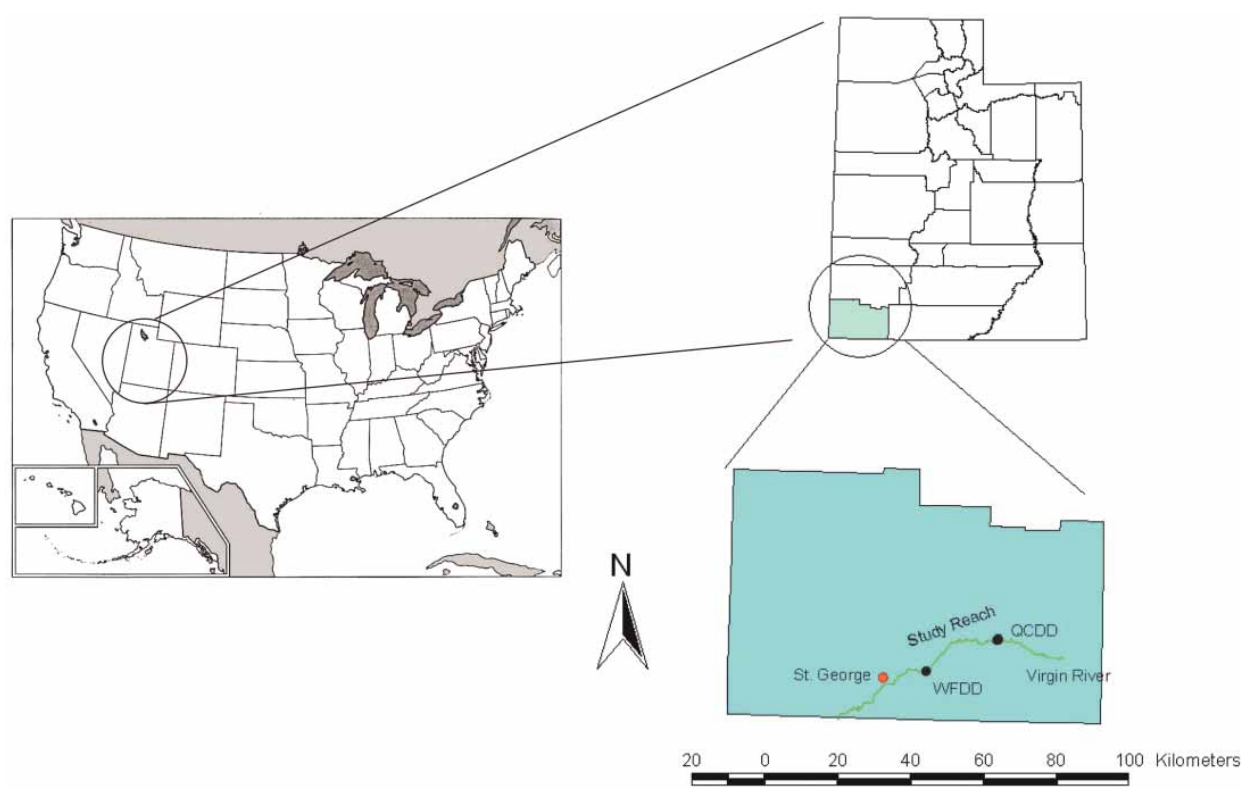

Figure 1 Geographic area - start of study reach is QCDD and the end of study reach is WFDD. 
may lead to localized high flow and flash flooding events in the Basin.

Population growth estimates for Washington County show that continued growth will occur and may increase to just over half a million by the year 2050. It is estimated that the need for water will exceed the current available supply by as much as 246.6 million cubic metres $\left(\mathrm{Mm}^{3}\right)(200,000 \mathrm{AF} / \mathrm{Yr})$ by 2050 (Boyle 1998). Scenarios tested were hypothetical operational changes that may be made by the Washington County Water Conservancy District (District). The District is primarily a water wholesaler to municipalities (WCWCD 2004).

The Virgin River Resource Management and Recovery Program (Program), formed in 1995, includes many interest groups whose common goals are related to aquatic species recovery (UDNR 2002) while managing water development within the Virgin River Basin. The District continues to play a key role within the Program and both entities are considering various options to reduce water temperatures and increase flows in the main stem Virgin River within the upper reaches of historical woundfin habitat, which partially lies within the study area. Two goals have been defined for the Program:
(1) implement actions to recover, conserve, enhance, and protect native species and (2) enhance the basin's ability to provide adequate water supplies for sustaining human needs (UDNR 2002).

Critical habitat designations were formalized in 2000 (USDI 2000) for the Threatened and Endangered species in the study area. This research focuses on the approximately $37 \mathrm{~km}$ of the upper end of historical woundfin and chub distributions and primarily lies between the Quail Creek diversion dam (QCDD) and the Washington Fields diversion dam (WFDD) (Figures 1 and 2).

Here we describe how this framework can be used to find trade-offs between the objective functions of net operational cost of the water system (to be minimized) and endangered fish thermal habitat (to be maximized) along approximately $25 \mathrm{~km}$ of the Virgin River. Constraints were those existing operational constraints contained in the simulation model, the maximum flow in potential future pipelines, and maximum water service area (SA) demand reductions. The optimization runs considered a simulation period from April to September, representing the hottest time of year in the Virgin River Basin. Scenarios consisted of base cases (undepleted river), two

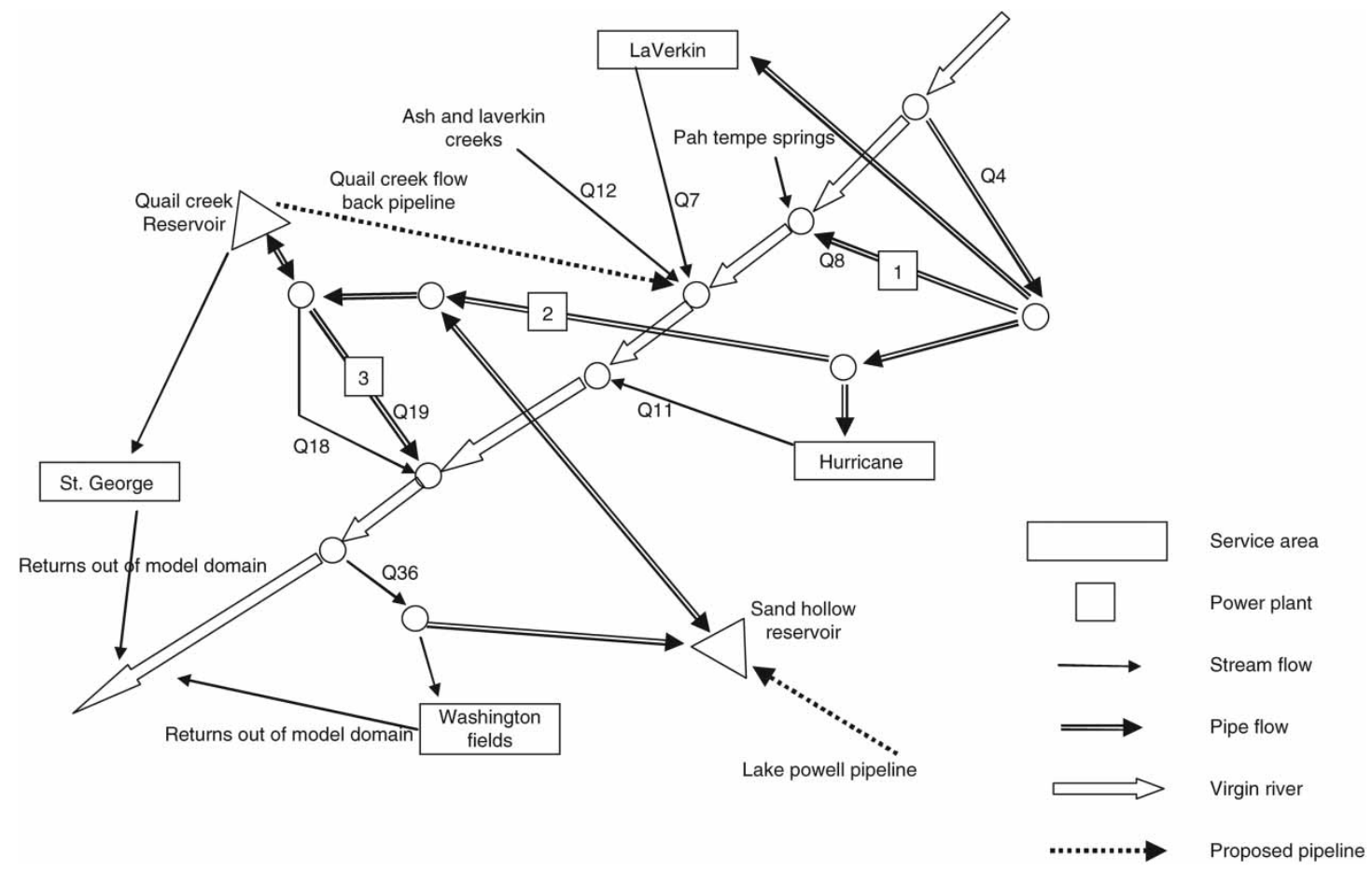

Figure 2 System schematic of GRES. QX4, Main Canal diversion from QCDD. Pah Tempe hot spring * (no QX designation) added at junction of QX's 2, 3, and 8. QX8, Hydro Plant 1 return to the river (physically below Pah Tempe springs); QX7, LaVerkin SA return to the river; QX11, Goulds Wash/Hurricane SA return to the river; QX12, Ash and LaVerkin creeks natural stream flow (Confluence Park); QX19, Hydro Plant 3 outflow to the river (Stratton Pond); QX18, Dam Seepage and spills in excess of Hydro Plant 3 to the river (from Quail Creek Reservoir); and QX36, The model stops at the WFDD junction. 
potential infrastructure configurations (considered at the time of this study) along with three hydrologic year types.

\section{Application to the Virgin River Basin}

Three existing models were integrated and then embedded into SCE for system optimization modelling. First, a mass balance model was used to model the operations of the water resource system on the main stem Virgin River from the QCDD downstream to the WFDD. Second, a temperature model capable of simulating maximum daily temperatures was coupled to the operations model. Third, an estimate of fish habitat for the endangered woundfin minnow was made with a newly developed temperature-based habitat suitability metric, all of which are described in Basdekas (2007).

\subsection{Operations model (GRES)}

The Virgin River Daily Operation Simulation model is a mean daily simulation model that is a specialized application of the Generalized Reservoir Operation Simulation Model (GRES) in the study area (Adams et al. 1992). The model incorporates 2 reservoirs, 4 SAs, 2 hydropower plants, 1 pumping station, and 45 flow paths (Figure 2). For the remainder of this paper, GRES will refer to the specialized application of the operations model to the Virgin River. Modifications were made to GRES to allow flows to be transferred directly into the temperature model.

Four SA demands were modified to have a delivery factor (decision variable), applied to the existing demand values in GRES. The four delivery factors serve to reduce the demand and thereby reduce stream flow depletions. GRES contained two operational options independent of one another that were of current interest to the District and Program which are the proposed Lake Powell to Sand Hollow Reservoir pipeline and the Quail Creek Reservoir to Confluence Park, flow back, pipeline (QCFB). The flow rates for these two pipelines were used as decision variables.

The Lake Powell to Sand Hollow Reservoir pipeline is proposed to convey a portion of Utah's Colorado River water allocation, for M\&I uses. This is significant in that the additional water will allow for continued growth in Washington County but may also help endangered species by allowing more flow to remain in the Virgin River. The additional flow, up to $2.74 \mathrm{~cm}$ (96.6 cfs), will not discharge directly into the Virgin River therefore it is not used as an input to the temperature model. However, the flow enters Sand Hollow reservoir where it is available for distribution to the SAs subject to the priority and rule system in GRES.

The QCFB pipeline name is due to its operation, specifically conveying water upstream from the main stem Virgin River discharge location (Figure 2). The purpose of the QCFB option is to add cooler water, up to $0.34 \mathrm{~cm}$ (12 cfs), to the Virgin River just below the Confluence Park area of the main stem Virgin River thereby providing a benefit to endangered species in the form of improved thermal habitat. The QCFB pipeline was added to the temperature model since it will discharge directly into the Virgin River.

\subsection{Temperature and habitat}

The temperature model selected and adapted for this study was developed by Neilson (2006). It operates on sub-daily time steps and can, therefore, simulate maximum daily water temperatures. The model is a one-dimensional, surface heat balance, and advective transport model utilizing a kinematic wave approach for flow routing. The model allows for different input time steps for meteorological data as well as point and distributed inflow sources. A single stream or river segment is divided into computational cells or elements; stream networks are not modelled and tributaries are treated as a time series input. For this study, hourly observed data, or estimates, were utilized. Here, the temperature model will be referred to as VR_Temp.

The temperature-based habitat suitability index metric (SI) was based on maximum daily temperatures, where the lower preferendum is determined using a regression equation with the 14-day average daily temperature as well as the maximum daily temperature. The lower preferendum is a moveable breakpoint reflecting the antecedent thermal history of the fish. The upper preferendum is a fixed point as is the critical thermal maximum (CTM). SI values between the lower and upper preferenda are assumed to be ideal and set at a maximum value of 1.0. SI values between zero and the lower preferendum as well as between the CTM and the upper preferendum are linearly interpolated between zero and one. Addley et al. (2005) describe laboratory experiments on growth rates of woundfin under different temperature and feeding rates. The underlying relationships between temperature and relative suitability were developed for an upper thermal preferendum and CTM based on preliminary results from Addley et al. (2005).

\subsection{Habitat objective function}

Suitability values were summed daily over the model domain for each of the 33 computational cells considered to have adequate physical habitat, out of a total of 47 computational cells. A minimum seven-day running average of the summed suitabilities for the habitat reach (i.e. the 33 computational cells) is then computed for the simulation period. For this study, there is a maximum possible value of 33 ; each computational cell has a maximum of 1 . A value of 33 indicates that at no time during the simulation did the suitabilities fall below one for any single computational cell. This minimum seven-day average is the 
metric that is used in the habitat objective function, shown in brackets [ ], in Eq. (1).

A transformation of the objective function was required to fit into the minimization scheme of the existing SCE algorithm. The minimum seven-day average of the sum of temperature suitability for the simulation was multiplied by $(-1)$, then 33 was added to the value of the habitat objective function, shown mathematically in Eq. (1). After completion of the model runs, the inverse transform was applied for the comparative assessments:

$$
\begin{aligned}
\text { Habitat objective function }= & {\left[\sum_{\text {day }=1}^{7}\left[\sum_{i=15}^{47} \mathrm{SI}(i)\right] / 7\right] *(-1) } \\
& +33
\end{aligned}
$$

where SI is the temperature suitability for an individual computational cell and $i$ the computational cell.

\subsection{Cost objective function}

The cost objective function, which is defined as net cost, is the difference between the variable operations and maintenance (O\&M) costs and hydropower revenue experienced by the District given existing infrastructure. Additionally, costs associated with operating potential infrastructure options are considered and the cost objective function is given in Eq. (2).

Variables in the cost objective function include annual O\&M costs associated with the existing District facilities. District O\&M costs include operation of the existing system as a whole, given a per unit basis of water assumed to be diverted from the QCDD. This does not include operation of the Sand Hollow system. The District did not have associated costs available at the time of this study. No annualized capital costs were used for new infrastructure options. The assumption was that for a single year evaluation, it was reasonable to assume that a project is built and then examine if there is a demand for water from the facility prior to more detailed life cycle cost estimates.

Boyle Engineering prepared a report (Boyle 2003) on the Lake Powell pipeline examining approximately 12 alignments and evaluating alternatives based on capital and O\&M costs and were used to develop the cost objective function. Alpha Engineering (unpublished report, 2004) prepared preliminary cost estimates evaluating three different alternatives for augmenting flow in the Confluence Park area downstream to Quail Creek Reservoir:

$$
\begin{aligned}
\mathrm{NETCOST}= & \left(\sum \text { LP_OM }-\sum \text { LP_Rev }\right)+\left(\sum \text { QCFB_OM }\right) \\
& +\left(\sum\left(\operatorname{SARED}(i)^{*} \mathrm{QDMIY}(i)^{*} \mathrm{WRcost}\right)\right) \\
& +\left(\text { existing_O } \& \mathrm{M}-\text { kwprice_hydro* } \sum \text { energy }\right),
\end{aligned}
$$

where the Lake Powell pipeline cost estimates were obtained and/or derived from Boyle (2003) and given as follows: LP_OM is Annual O\&M; for simulation year only, LP_OM = LP_Days/year_OMDays * LP_OMrate * QLPOWLL/ LP_QMAX, and LP_OM_Fix is Annual O\&M fixed costs = $\$ 792,000$, where LP_Days is the number of days the pipeline is conveying water, year_OMDays is the total possible days pipeline can be in operation (there is an internal constraint to limit the flow of water from Lake Powell if Sand Hollow reservoir is above a specified storage value), LP_OMrate is the O\&M rate $=\$ 8,610,000 /$ year, QLPOWLL is the actual average flow rate; decision variable, LP_QMAX is the maximum flow rate $=2.74 \mathrm{~cm}(96.7 \mathrm{cfs})$, and LP_Rev the Lake Powell pipeline annual power revenue; simulation year only

$$
\begin{aligned}
& \text { LP_Rev = LP_Days/year_OMDays* } \\
& \text { LP_Revrate*QLPOWLL/LP_QMAX, }
\end{aligned}
$$

where LP_Revrate is the revenue rate from power generation $=$ $\$ 8,647,000 /$ year.

Rate is adjusted by the ratio of days used to days in the year as well as the ratio of actual flow to maximum flow. It is understood that these relationships may not be linear, but they are used here due to the lack of additional information.

The Quail Creek flow back pipeline associated costs are shown below:

QCFB_OM is the Annual O\&M; for the temperature simulation year only $=\$ 424.77 /$ day, based on power costs from Boyle (2003), and is adjusted by the ratio of flow to maximum flow capacity.

No fixed costs for maintenance were provided with cost estimates for QCFB, but were considered minimal given the small size of the project and given the assumptions for these simulations, i.e. single year. Additionally, any flow less than the value of the decision variable is tracked and the O\&M adjusted accordingly. Associated costs used in this study were obtained from the District (personal communication, 2004) and are as follows:

$\operatorname{SARED}(i)$ is the delivery factor for reduction of SA demands for each area $(0.85-1.0)$ and WRcost is the cost of buying water, i.e. demand reduction $\$ 1000 / 1233 \mathrm{~m}^{3}$ (\$1000/ acre $\left.\mathrm{ft}\right)$.

O\&M figures were obtained from the District (personal communication, 2004) and are as follows:

- $\$ 73.19 / 1233 \mathrm{~m}^{3}$ (\$73.19/acre $\left.\mathrm{ft}\right)$ applied to the Main canal diversion (QCDD);

- kwprice_hydropower $(\$ 0.07 / \mathrm{kW} \mathrm{hr})$;

- annual SA water demand - scenario dependant; and

- energy - total energy produced from all power plants (from GRES) revenue used to offset other O\&M costs. 
Table 1 Model simulation scenarios

\begin{tabular}{llll}
\hline Scenario & Hydrologic year type & Demand case & \multicolumn{1}{c}{ Name } \\
\hline 1 & Drought 2003 & Existing & Existing 2003 \\
2 & Average 1997 & Existing & Average 1997 \\
3 & Wet 1995 & Existing & Wet 1995 \\
4 & Drought 2003 & Future & Future 2003 \\
\hline
\end{tabular}

The combinations of operational options and water year types simulated in this study are shown in Table 1.

\subsection{Implementation of scenarios}

Institutional instream flow constraints that are internal to the model such as the existing flow requirements of $.085 \mathrm{~cm}(3$ cfs) below the QCDD and $2.44 \mathrm{~cm}(86 \mathrm{cfs})$ at the WFDD were not changed during the simulations. Decision variables are those system features in a simulation model that may change how the system is operated. For this study, decision variables include reduction of SA demands, the proposed addition of the Quail Creek flow back pipeline, and the Lake Powell pipeline as well as the flow rates within those proposed pipelines.

Decision variables are those variables under the control of the optimization model. Those variables are selected and a simulation is performed for the April to September time period for each scenario. The decision variables used in this study relate to system operations and are as follows:

(1) Four delivery factors to reduce the water SA demand for each of the SAs (range from 0.85 to 1.0 ; which allows for a $15 \%$ reduction).

(2) The amount of water delivered through proposed infrastructure, from zero up to the maximum capacity of $0.34 \mathrm{~cm}$ for the QCFB and $2.74 \mathrm{~cm}$ for the proposed Lake Powell pipeline (future demand scenario only).

Three representative hydrologic year types, using existing SA demands, were modelled; drought, average, and wet. USGS Virgin River gauge data were obtained for water years 1995 (representing a wet year) and 1997 (representing a typical year) corresponding to annual flow exceedence values of approximately $13 \%$ and $61 \%$, respectively. Hydrology for the drought year of 2003 had an exceedence value of approximately $97 \%$. Due to limited historical solar radiation data, all necessary meteorological data from 2003 were used as meteorology inputs for all other hydrologic year types. An additional scenario was evaluated using a future demand condition along with drought hydrology.
The basic procedural steps for the simulation and optimization modelling are as follows:

(1) Randomly select initial values for all decision variables (different random seed for each variable to reduce chances of developing artificial relationships between decision variables).

(2) Run GRES and pass resulting flows to the VR_Temp.

(3) Run VR_Temp with flows received from GRES.

(4) Calculate the habitat metric.

(5) Evaluate objective functions and pass results back to SCE.

(6) SCE will select new decision variables.

(7) Repeat until convergence (less $0.001 \%$ change in consecutive objective function values) or the maximum number of function evaluations is reached (fixed to be 5000).

\subsubsection{Simulation methods}

The four scenario runs were carried out by using different percentage weights on the cost and habitat objective functions as shown in Table 2. The naming is indicative of the relative weighting on cost and habitat. For example, the $90 \mathrm{C} 10 \mathrm{H}$ runs identifies an optimization run with $90 \%$ weighting on cost and $10 \%$ on habitat. Two additional points were calculated $(90 \mathrm{C} 10 \mathrm{H}$ and 10C_90H) for the existing 2003 scenario to better approximate the Pareto front. Each scenario was optimized three times, each with a different random restart to help avoid results that depend upon initial conditions.

\subsubsection{Base case conditions}

The base case condition simulation consisted of setting SA demands, initial reservoir storages and, power house capacities all to zero. These base case simulations were effectively simulating an undepleted river flow condition with no optimization. Base case conditions were estimated through simulations for each of the

Table 2 Weighting run naming conventions for all scenarios

\begin{tabular}{lccc}
\hline $\begin{array}{l}\text { Cost weight } \\
(\%)\end{array}$ & $\begin{array}{c}\text { Habitat } \\
\text { weight }(\%)\end{array}$ & $\begin{array}{c}\text { Weighting } \\
\text { run name }\end{array}$ & Designation $^{\mathrm{a}}$ \\
\hline 100 & 0 & $100 \mathrm{C} \_0 \mathrm{H}$ & $\mathrm{A}$ \\
90 & 10 & $90 \mathrm{C} \_10 \mathrm{H}^{\mathrm{b}}$ & $\mathrm{B}$ \\
75 & 25 & $75 \mathrm{C} \_25 \mathrm{H}$ & $\mathrm{C}$ \\
50 & 50 & $50 \mathrm{C} \_50 \mathrm{H}$ & $\mathrm{D}$ \\
25 & 75 & $25 \mathrm{C} \_75 \mathrm{H}$ & $\mathrm{E}$ \\
10 & 90 & $10 \mathrm{C} \_90 \mathrm{H}^{\mathrm{b}}$ & $\mathrm{F}$ \\
0 & 100 & $0 \mathrm{C} \_100 \mathrm{H}$ & $\mathrm{G}$ \\
\hline
\end{tabular}

Note: All scenarios will use the same run naming convention within their respective sub-sections for discussion and analysis.

${ }^{\mathrm{a}}$ Corresponds to point locations in Figure 3.

${ }^{\mathrm{b}}$ The 90C_10H and 10C_90H were only run for the Existing 2003 scenario. 
three hydrologic year types, i.e. the drought, average, and wet years had their own hydrologic base cases. These base cases would be the basis of comparisons for the respective hydrologic year type scenarios. The resulting flow values were then run through VR_Temp using 2003 meteorology data for the three hydrologic year types since complete data were missing for the other year types. Using the 2003 data, in this fashion, is considered to be an acceptable method since it represents a somewhat conservative approach regarding species protection, i.e. hot year. Bimonthly exceedence values for air temperatures were calculated and on average equalled nearly $25 \%$, resulting in temperatures generally being significantly higher than the median.

\section{Results/discussion}

For all scenarios, two basic types of analyses were performed. First, a detailed treatment of results with the intent of giving the reader insights into how one may evaluate cost, in dollar terms, and quantified fish habitat. Second, impacts to fish habitat were assessed by the use of exceedence plots and event summary plots. An event is defined as a one hour time period when the hourly maximum allowable temperature of $32.2^{\circ} \mathrm{C}$ was exceeded which is the upper limit of the defined thermal suitability range for woundfin. When this water temperature was exceeded, the result was a zero value for SI for that time period. Three plots were used to assess the longitudinal or spatial distribution of the number of events, the maximum duration and the average duration of an event such as those shown in Figures 5-7.

Specifics of each scenario will be discussed in greater detail later but, in general, the Pareto front was defined by two end points (100C_0H and $0 \mathrm{C}_{-} 100 \mathrm{H}$ weighting runs) and a clustering of all other points in the compromise region for all scenarios. Given any allowance for habitat in the objective function, the modelling framework maximizes the flow in the QCFB pipeline to its maximum capacity of $0.34 \mathrm{~cm}$ (12 cfs). This was due to the efficiency of the pipeline's ability to deliver cooler water in a cost effective manner. Due to the similar nature of the response surfaces within scenarios, the discussion is generally limited to the 50C_50H weighting runs to describe the compromise region between the end points. The number of simulation trials to convergence varied between approximately 1500 and 2500 depending on scenario. Thus, the stoppage criterion was the convergence within $0.001 \%$ of the change between consecutive objective function values.

\subsection{Existing 2003 scenario}

The Existing 2003 drought scenario used existing SA demands along with 2003 hydrology. This scenario was implemented first

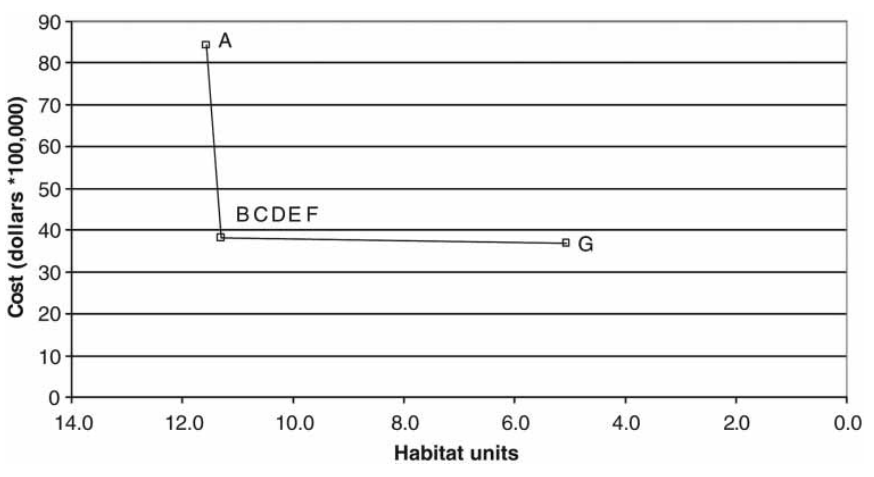

Figure 3 Pareto front for existing 2003 scenario and corresponds to Tables 2 and 3.

and utilized the highest number of weighting schemes, in an attempt to more fully define a Pareto front. As seen in Table 3, the same decision variable values were determined for weighting runs during the optimization process, except for the 100C_0H and the $0 \mathrm{C}_{-} 100 \mathrm{H}$ weighting runs. One of the most interesting results is in the $0 \mathrm{C}_{-} 100 \mathrm{H}$ simulation where there were changes in the SA delivery factors. The naming scheme SA1-SA4 corresponds to SAs 1-4. The delivery factor SA3 value is 1.0 , whereas for SA1 and SA2 values are 0.85 , the lowest possible value. The value for SA4 was less than one but varied slightly. Additional analyses revealed that the SAs obtain flow via the same section of river where an instream flow requirement exists, assuring sufficient water for SA3. The remainder of this scenario analysis focuses on computational cells corresponding to selected physical locations of interest within the habitat reach.

Given any allowance for habitat in the objective function, the modelling framework maximizes the flow in the QCFB pipeline to its capacity of $0.34 \mathrm{~cm}$ (12 cfs) due to the efficiency of the QCFB in delivering relatively low cost per habitat unit as compared with other flow enhancement options. This Pareto front behaviour was partly the motivation for adding the two additional weighting runs of $90 \mathrm{C}_{-} 10 \mathrm{H}$ and $10 \mathrm{C} \_90 \mathrm{H}$ and this is shown graphically in Figure 3. In order to verify that the optimization was not simply returning values near the constraint for the decision variable, the high constraint of $.34 \mathrm{~cm}$ (12 cfs) was increased to $1.4 \mathrm{~cm}$ (50 cfs), well over the proposed design value. When the constraint was increased, the optimized delivery values for 50C_50H weighting run increased to $0.18 \mathrm{~cm}$ (44 cfs) and were no longer equal to the high constraint as had been previously observed for the same weighting run. This response represents an important verification of the proper function of the optimization modelling.

\subsubsection{Existing 2003 habitat exceedence plots}

Figure 4 shows the habitat exceedence plot of the temperaturebased habitat suitability metric. The $100 \mathrm{C} \_0 \mathrm{H}$ run produced 

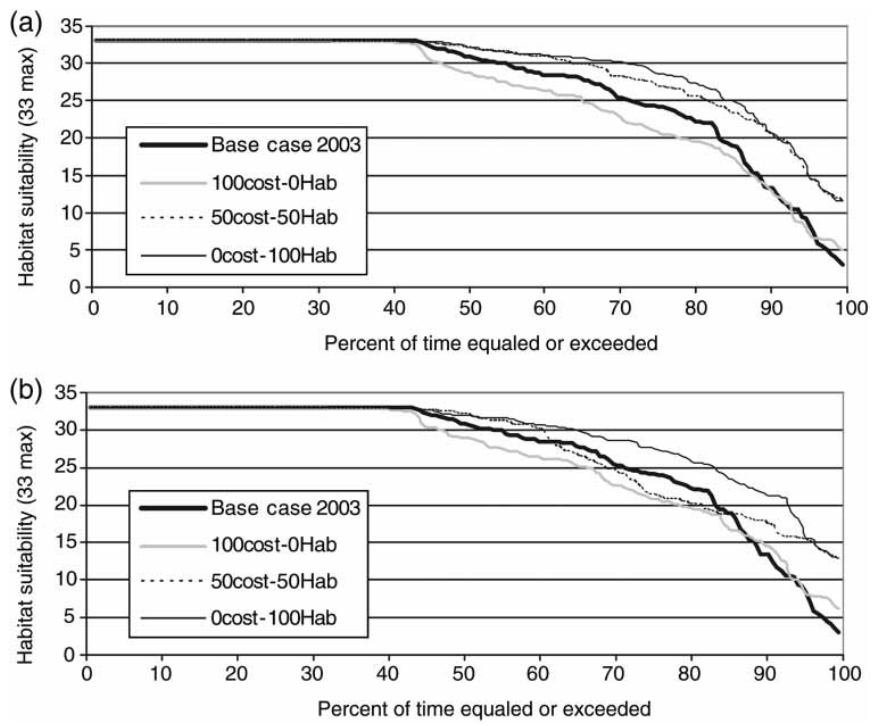

Figure 4 (a) Existing 2003 scenario exceedence plot of temperaturebased habitat suitability metric. (b) Future 2003 scenario exceedence plot of temperature-based habitat suitability metric.
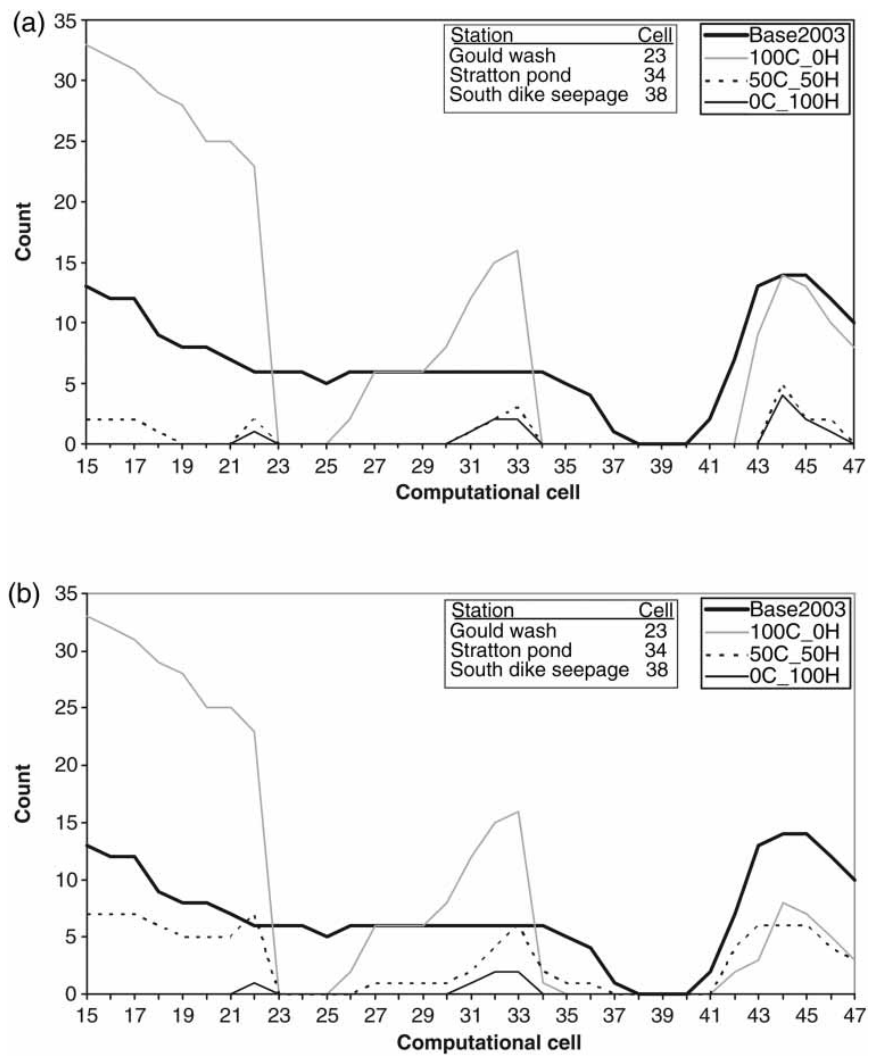

Figure 5 (a) Existing 2003 scenario run sum plot of number of events exceeding allowable temperature of $32.2^{\circ} \mathrm{C}$, the upper limit of the defined thermal suitability range for woundfin. (b) Future 2003 scenario run sum plot of number of events exceeding allowable temperature of $32.2^{\circ} \mathrm{C}$, the upper limit of the defined thermal suitability range for woundfin.
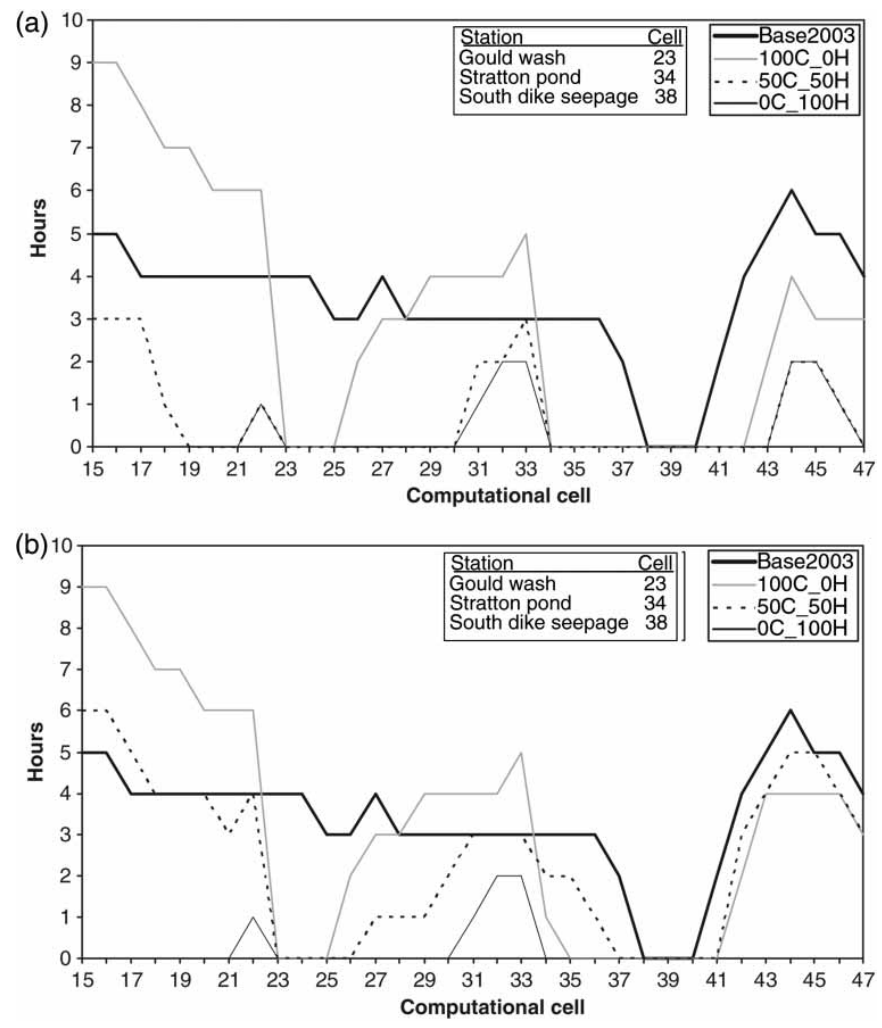

Figure 6 (a) Existing 2003 scenario run sum plot of maximum event length for temperature exceeding allowable temperature of $32.2^{\circ} \mathrm{C}$, the upper limit of the defined thermal suitability range for woundfin. (b) Future 2003 scenario run sum plot of maximum event length for temperature exceeding allowable temperature of $32.2^{\circ} \mathrm{C}$, the upper limit of the defined thermal suitability range for woundfin.

less habitat than the base case except at the high end of the exceedence values. The reason for this difference is due to the WFDD flow requirement and storage capability of Quail Creek Reservoir which allows for flow augmentation below Stratton Pond. The $50 \mathrm{C} \_50 \mathrm{H}$ and the $0 \mathrm{C}_{-} 100 \mathrm{H}$ runs produced more habitat than the base case condition. It is interesting to note that $40 \%$ of the time the habitat value is at the maximum value, even for the base case, suggesting that the period of pipeline operation should be re-examined. This does not suggest that the scenarios should be considered equal as the high exceedence end of the curve shows more than double the habitat with the QCFB pipeline active as opposed to inactive as in the $100 \mathrm{C} \_\mathrm{OH}$ run.

\subsubsection{Existing 2003 event summary plots}

Event summary plots for habitat were generated to examine event count, maximum length, and average length shown in Figures 5-7, respectively. Except for the 100C_0H run, this scenario shows a reduction in the number of events, the maximum event duration and the average event duration, as compared with the corresponding base case. The $100 \mathrm{C} \_\mathrm{OH}$ 

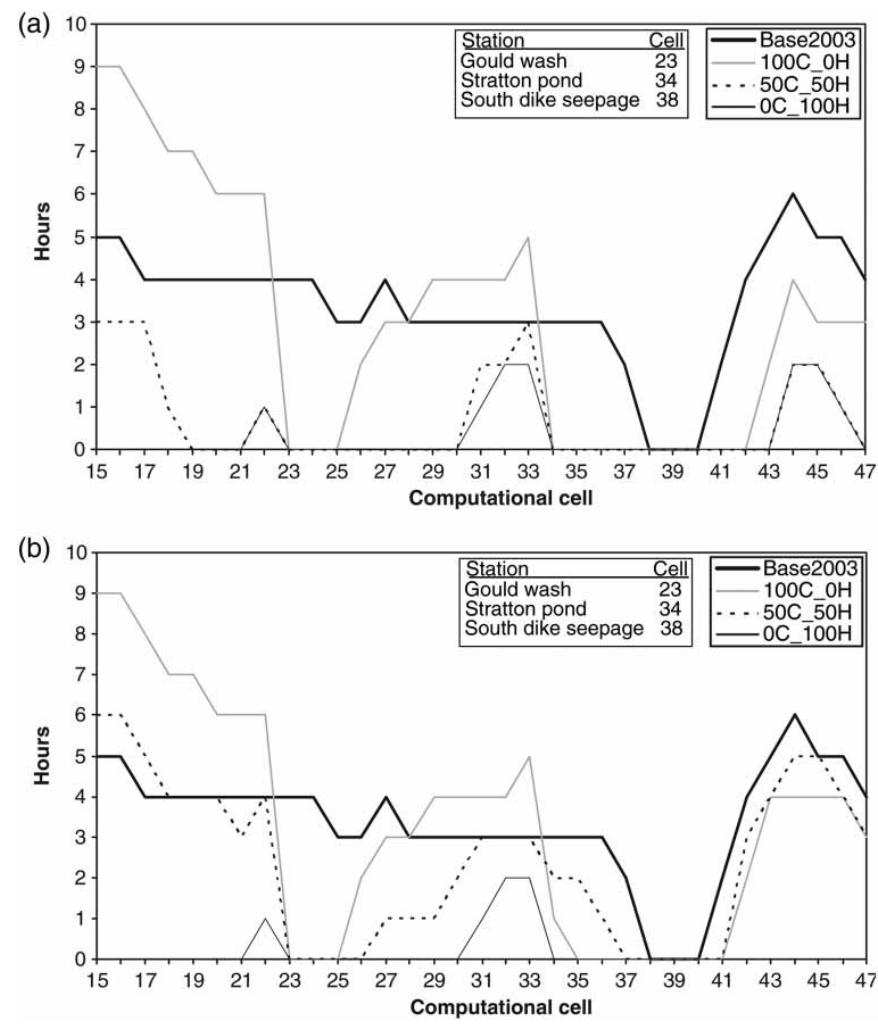

Figure 7 (a) Existing 2003 scenario run sum plot of the average event length for temperature exceeding allowable temperature of $32.2^{\circ} \mathrm{C}$, the upper limit of the defined thermal suitability range for woundfin. (b) Future 2003 scenario run sum plot of the average event length for temperature exceeding allowable temperature of $32.2^{\circ} \mathrm{C}$, the upper limit of the defined thermal suitability range for woundfin.

run is worse in the three measures in the beginning and the middle of the simulation reach. This is attributed to the lack of effects from the QCFB pipeline. At computational cell 23, Gould Wash enters the river, resulting in fewer events than the base case run. There is an increase in the number of events and duration until about cell 34, where Stratton Pond inflow occurs. While all of the weighted run scenarios for all three metrics are lower than the base case at this point, the $100 \mathrm{C}_{-} \mathrm{OH}$ run is still the highest due to the effects of no QCFB pipeline discharge. An interesting result in the base case versus the other run scenarios is located at computational cell 38. The count of events drops to zero and then increases at cell 41 . The reason is a very subtle change in temperature that occurs in this reach. There are small ground water accretions applied at cell 40 . Cell 41 corresponds to the beginning of a groundwater losing reach of the Virgin River. Additionally, those events are occurring due to simulated temperatures exceeding the threshold by a range of $0.14-0.002^{\circ} \mathrm{C}$. Those water temperatures are also the peak temperatures for the day and begin cooling over time as well as space (i.e. the cell picks up just enough cooler water to drop back below the threshold). If not for the small amount of groundwater, it is likely that there would be events occurring all along the reach. This response demonstrates that when models such as these are used for policy determination, the modeller must communicate the binary nature of triggers so that appropriate factors of safety are built into the metrics and policy triggers.

\subsubsection{Existing 2003 cost and habitat trade-offs}

Table 4 contains results from using different weights to define a Pareto front between cost and habitat as well as the quotient of cost divided by habitat that forms a new unit for discussion, the cost per habitat unit (cost/habitat). This cost/habitat unit resultant metric is used for the remaining scenarios. It can be seen that a significant amount of habitat can be gained by implementing the QCFB option and running 150 days for an additional net cost of approximately $\$ 125,000$. The cost/habitat unit decreases from $\$ 729,000 /$ unit to $\$ 337,000 /$ unit. The habitat gained increases from 5.1 to 11.3 units. These results strongly suggest that this option would be one operational alternative that may warrant further exploration.

The $0 C_{-} 100 \mathrm{H}$ weighting run produces more habitat (11.8 units) for the trade-off in additional net cost of approximately $\$ 4.6$ million as compared with the $50 \mathrm{C} \_50 \mathrm{H}$ run. The cost/ habitat unit increases from $\$ 337,000 /$ unit to $\$ 728,000$ /unit for a small gain in habitat of 0.3 units. It is an interesting coincidence that the cost/habitat unit is nearly identical in the extreme runs of $100 \mathrm{C} \_\mathrm{H}$ and $0 \mathrm{C}_{-} 100 \mathrm{H}$ yet the latter has nearly 2.3 times the quantity of habitat. This result demonstrates the need to not

Table 3 Existing 2003 summary of the average of model parameters for 1 April-30 September 2003

\begin{tabular}{llllllll}
\hline Weighting & Cost & Habitat & QCFB & SA1 & SA2 & SA3 & SA4 \\
\hline 100C_0H & 36.86 & 5.05 & 0 & 1 & 1 & 1 & 1 \\
All others & 38.12 & 11.3 & 0.34 & 1 & 1 & 1 & 1 \\
0C_100H & 84.26 & 11.57 & 0.34 & 0.85 & 0.85 & 1 & $0.920^{\mathrm{a}}$ \\
\hline
\end{tabular}

Notes: Cost in dollars* 100,000. QCFB values are in cms. Habitat units maximum value of 33. SA1-SA4 are per cent of full demand values for the respective SAs. ${ }^{a}$ Value range was $0.87-0.98$. This may indicate relative insensitivity to this parameter. 
Table 4 Existing 2003 net cost and habitat units (average reported)

\begin{tabular}{lcccc}
\hline Weighting & $\begin{array}{c}\text { QCFB } \\
\text { pipeline } \\
\text { run }\end{array}$ & $\begin{array}{c}\text { Net cost } \\
100,000 \\
\text { (dollars) }\end{array}$ & $\begin{array}{c}\text { Habitat } \\
\text { units }\end{array}$ & $\begin{array}{c}\text { Cost/ } \\
\text { habitat } \\
\text { unit }\end{array}$ \\
\hline 100C_0H & 0.00 & 36.86 & 5.1 & 7.29 \\
50C_50H & 0.34 & 38.12 & 11.3 & 3.37 \\
0C_100H & 0.34 & 84.26 & 11.6 & 7.28 \\
\hline
\end{tabular}

Note: 50C_50H is representative of all simulation between the bounds.

examine the objective functions only, other metrics and system state variables, pertinent to the problem at hand, are required for complete system analysis.

\subsection{Average 1997 scenario}

The time series plots of simulated water temperatures (not shown here) typically showed that the relative differences between weighting runs narrowed. Additionally, the influence of the QCFB pipeline diminished more at the Stratton Pond location for the 1997 average year hydrology as compared with the 2003 dry year hydrology, most noticeably for the 2 June through 4 August time period. The habitat exceedence plots for this scenario were similar to that of the Existing 2003 scenario in relative performance except that the 100C_0H run at no time exceeded the base case condition. These results are intuitively consistent with a wetter year type with corresponding larger river flows.

\subsubsection{Average 1997 event summary plots}

The number of events in which the water temperature exceeded upper critical temperatures defined by the habitat function, for the different weighting runs, were generally all less than the base case except for the $100 \mathrm{C} \_0 \mathrm{H}$ weighting run. This is in good agreement with the habitat exceedence plots. The only odd occurrence seems to be at the end of the study reach where the $0 \mathrm{C} \_100 \mathrm{H}$ weighting run is below the $50 \mathrm{H} \_50 \mathrm{C}$ weighting run but only by one event at two spatial locations. These differences are attributed to a similar sensitivity near the maximum threshold and are not considered significant differences with respect to the number and duration of events between the 50C_50H and $0 \mathrm{C} \_100 \mathrm{H}$ weighting runs.

\subsubsection{Average 1997 cost and habitat trade-offs}

Table 5 shows the cost/habitat unit and shows that a significant amount of habitat can be gained by running the QCFB 183 days for an additional net cost of approximately $\$ 130,000$. The cost/habitat unit decreases from $\$ 865,000$ /unit to $\$ 407,000 /$ unit and the habitat gained increases from 5.83 to 12.74 units. The $0 \mathrm{C} \_100 \mathrm{H}$ weighting run produces the most habitat, at 12.82
Table 5 Average 1997 net cost and habitat units (average reported)

\begin{tabular}{lcccc}
\hline Weighting & $\begin{array}{c}\text { QCFB } \\
\text { pipeline } \\
\text { run }\end{array}$ & $\begin{array}{c}\text { Net cost* } \\
100,000 \\
\text { (dollars) }\end{array}$ & Habitat & $\begin{array}{c}\text { Cost/ } \\
\text { habitat } \\
\text { unit }\end{array}$ \\
\hline 100C_0H & 0.00 & 50.50 & 5.83 & 8.65 \\
50C_50H & 0.34 & 51.80 & 12.74 & 4.07 \\
0C_100H & 0.34 & 108.36 & 12.82 & 8.45 \\
\hline
\end{tabular}

Note: $25 \mathrm{C} \_75 \mathrm{H}$ and $75 \mathrm{C} \_25 \mathrm{H}$ were essentially identical to $50 \mathrm{C} \_50 \mathrm{H}$.

units for a trade-off of an additional net cost of approximately 5.7 million dollars as compared with the 50C_50H run. The cost/habitat unit increases from $\$ 407,000 /$ unit to $\$ 845,000 /$ unit for a small gain in habitat of 0.1 units. It is interesting to note that the cost/habitat unit is very close between the extreme runs of $100 \mathrm{C} \_0 \mathrm{H}$ and $0 \mathrm{C} \_100 \mathrm{H}$ yet the latter has slightly more than twice the amount of habitat.

\subsection{Wet hydrology 1995 scenario}

The time series plots for the wet hydrology year of 1995 show results that would be typically expected as compared with the drought and average year simulations. The influence of the QCFB pipeline is less at the below Confluence Park station as well as at the Stratton Pond location for the wet hydrology as compared with the drought and average hydrology. The $50 \mathrm{C} \_50 \mathrm{H}$ and $0 \mathrm{C} \_100 \mathrm{H}$ weighting runs both showed beneficial temperature differences in the below Confluence Park station. The reasons and implications are described in the following sections.

\subsubsection{Wet 1995 event summary plots}

The habitat exceedence plots show that the $100 \mathrm{C} \_\mathrm{OH}$ has the least overall quantity of habitat with the $0 \mathrm{C}_{-} 100 \mathrm{H}$ and $50 \mathrm{C} \_50 \mathrm{H}$ weighting runs being similar. However, an interesting result differing from the other two hydrology scenarios is that the base case has more habitat except above the $98 \%$ exceedence level. The average separation between the $75 \%$ and $95 \%$ exceedence levels is approximately 1.9 habitat units between the base case and both the $0 \mathrm{C}_{-} 100 \mathrm{H}$ and $50 \mathrm{C} \_50 \mathrm{H}$ weighting runs. For the 50C_50H weighting run, in July and August, all the flows except for the $0.08 \mathrm{~cm}$ ( $3 \mathrm{cfs}$ ) minimum requirement, is being diverted. The average flow for July is $4.04 \mathrm{~cm}(142.7 \mathrm{cfs})$ and $2.71 \mathrm{~cm}$ (95.8 cfs) for August which remains in the Virgin River under the base case condition. Even though the QCFB is running, the resulting low flow water temperature is still warmer than the full natural flow routing through the system. So this is not necessarily a result of a negative effect of the habitat component in the objective function (i.e. QCFB pipeline 
Table 6 Wet 1995 net cost and habitat units (average reported)

\begin{tabular}{lcccc}
\hline Weighting & $\begin{array}{c}\text { QCFB } \\
\text { pipeline } \\
\text { run }\end{array}$ & $\begin{array}{c}\text { Net cost } * \\
100,000 \\
\text { (dollars) }\end{array}$ & Habitat & $\begin{array}{c}\text { Cost/ } \\
\text { habitat } \\
\text { unit }\end{array}$ \\
\hline 100C_0H & 0.00 & 63.69 & 14.15 & 4.50 \\
50C_50H & 0.34 & 65.88 & 21.28 & 3.10 \\
0C_100H & 0.34 & 185.74 & 21.28 & 8.73 \\
\hline
\end{tabular}

Note: $25 \mathrm{C} \_75 \mathrm{H}$ and $75 \mathrm{C} \_25 \mathrm{H}$ were essentially identical to $50 \mathrm{C} \_50 \mathrm{H}$.

flow) rather the extreme reduction of flows from the natural flow condition. The delivery factor for SA1 stayed at 1.0 where in other hydrologic year types it was around 0.85 . It may be possible that the optimization model needed more restarts as it may have been trapped in local optima, a topic of future research.

The event summary plots showed the $100 \mathrm{C} \_\mathrm{OH}$ was consistent with previous scenarios being worst for habitat quantity and quality. For the 50C_50H and 100C_0H weighting runs, there was only one event that occurred for one hour.

\subsubsection{Wet 1995 cost and habitat trade-offs}

Table 6 contains the cost/habitat results which indicate that a significant amount of habitat can be gained by implementing the QCFB running for 183 days resulting in an additional net cost of approximately $\$ 219,000$. The cost/habitat unit decreases from $\$ 450,000 /$ unit to $\$ 310,000 /$ unit. The habitat gained increases from 14.15 to 21.28 units. The $0 \mathrm{C}_{-} 100 \mathrm{H}$ weighting run produces essentially the same habitat as the $50 \mathrm{C} \_50 \mathrm{H}$ run at 21.28 units, for the trade-off in additional net cost of approximately $\$ 12.0$ million.

\subsection{Future 2003 scenario}

This scenario utilizes 2003 drought hydrology and future estimates of SA demands obtained from the District. St. George demands were increased from 25,600 $\mathrm{AF}$ to 76,697 $\mathrm{AF}$ and Washington Fields increased from 62,302 AF to 74,406 AF. The Lake Powell pipeline and the Quail Creek flow back pipeline options are both available with their full capacities of $2.74 \mathrm{~cm}$ (96.6 cfs) and $0.34 \mathrm{~cm}(12 \mathrm{cfs})$, respectively.

\subsubsection{Future 2003 event summary plots}

The weighting run plots are consistent with the existing condition plots as the available habitat increases with increases in the habitat weighting. The base case condition still provides more habitat than the $100 \mathrm{C} \_0 \mathrm{H}$ weighting run generally below the $85 \%$ exceedence level. The $50 \mathrm{C} \_50 \mathrm{H}$ weighting run exhibits more habitat than the base case plots except between the $63 \%$ and
$85 \%$ exceedence levels with the largest difference of approximately two habitat units.

More insight between the weighting runs was gained by reviewing the event summary plots. The number of events for the $0 \mathrm{C} \_100 \mathrm{H}$ and $50 \mathrm{C} \_50 \mathrm{H}$ weighting runs are similar to the existing conditions drought scenario for the same weights except in the lower part of the study reach where fewer events occur for the future condition scenario. The number of events increases for the 50C_50H weighting run as compared with the existing conditions scenario. For the maximum and average event durations, the $50 \mathrm{C} \_50 \mathrm{H}$ weighting run exceeded the $100 \mathrm{C} \_\mathrm{H}$ weighting run as well as the base case condition runs. Several potential causes for the results were found.

For the 50C_50H simulation, the QCFB flow stops 33 days before the $0 \mathrm{C}_{-} 100 \mathrm{H}$ weighting run which stopped at day 145 of the simulation. With QCFB flowing, Quail Creek reservoir is being depleted and storage cannot replenish due to lack of natural flow in meeting the WFDD minimum flow requirement.

\subsubsection{Future 2003 cost and habitat trade-offs}

A significant amount of habitat can be gained by implementing the QCFB. With the QCFB flow releases operating for 112 days, an additional net cost of approximately $\$ 110,000$ is incurred and the resulting cost/habitat unit decreases from $\$ 700,000 /$ unit to $\$ 358,000 /$ unit. The habitat gained increases from 6.3 to 12.6 units. The $0 \mathrm{C}_{-} 100 \mathrm{H}$ weighting run produces more habitat, at 12.8 units for a trade-off in additional net cost of approximately $\$ 9.6$ million, as compared with the 50C_50H run. The cost/habitat unit increases from $\$ 358,000 /$ unit to $\$ 1.1$ million/unit for a small gain in habitat of 0.2 units. From the $100 \mathrm{C} \_0 \mathrm{H}$ to the $50 \mathrm{C} \_50 \mathrm{H}$ run, there is an increase of nearly 2.0 times the quantity of habitat for an additional net cost of approximately $\$ 17,500$ /additional habitat unit.

\section{Summary and conclusions}

A framework was developed and applied as a proof of concept that allows for the evaluation of different management options including new infrastructure and/or target environmental flows based on simulated maximum daily water temperatures. This framework allows for testing alternatives and optimizing the operations of a water management system while minimizing cost and maximizing endangered fish thermal habitat. A single objective global optimization algorithm was used in conjunction with a percentage weighting scheme to approximate a Pareto front of net costs and habitat units. Options for optimization or decision variables included reduction of SA demands, the proposed addition of the Quail Creek flow back pipeline, and the Lake Powell pipeline, as well as the flow rates within the proposed pipelines. 
One of the most interesting results from the Existing 2003 scenario was how current operations provided equal or more habitat at the high exceedence flow values, than the base case condition with no diversions or reservoirs. The additional habitat gained by having a $2.44 \mathrm{~cm}$ ( $86 \mathrm{cfs}$ ) flow requirement at WFDD basically ensures that part of the summer time flows are high enough to positively impact the water temperatures as compared with the base case conditions. Base case conditions were developed by setting SA demands, initial reservoir storages and, power house capacities all to zero, effectively simulating an undepleted river flow condition. As expected from first principals, the results show that, the higher the thermal mass in the river, everything else being equal, the lower the maximum daily temperatures will be.

Generally, with the addition of any amount of weighting for the habitat in the objective function, the QCFB pipeline operates at its design capacity of $0.34 \mathrm{~cm}$ and results in solutions clustering in the compromise region. This was due to the efficiency of the pipeline's ability to deliver cooler water in a cost effective manner.

Generally, the use of the QCFB pipeline resulted in a much lower cost per habitat unit as well as increased habitat as compared with other options. This response is likely to be due in part to the cost used for pumping the water upstream to the Confluence Park area. Power costs used for pumping were those obtained from Boyle (2003) and not those used in the unpublished Alpha Engineering (2004) regarding QCFB pipeline alternatives. It was also found that under certain circumstances, the QCFB can result in exceedences in the maximum water temperature later in the year due to depleted reservoir storage which is a limitation in the approach of using a constant cold water release analogous to a minimum instream flow.

Generally, average and wet year types produced more habitat due to increased natural river flows as would be expected. The relative response between weighting runs within these twoyear types were similar to that observed for drought years except for the $100 \mathrm{C} \_0 \mathrm{H}$ runs. The $100 \mathrm{C} \_0 \mathrm{H}$ run was consistently lower than the base case condition for the average and wet year hydrology. In the wet year hydrology scenario, the base case always provided for the most habitat except at the extreme high end of the exceedence plots. We have also demonstrated the need to not only examine the objective functions, but other metrics and system state variables, pertinent to the problem at hand, are required for complete system analysis.

Future work could include sensitivity studies to determine the range of benefits from various releases of water from QCFB pipeline for different mainstem flow conditions. Those results could in turn be used to develop instream flow and temperature triggers for the optimal use of a cold water pool dedicated to habitat mitigation. New and more sophisticated multi-objective optimization algorithms are currently available that were not at the time of this study. If operational policies and infrastructure continue to be considered, then we would recommend this work to continue with those new tools taking advantage of their abilities to more efficiently approximate complex Pareto fronts.

It is incumbent on the engineer working with biological systems to evaluate modelling results in ways that may not be typical in the engineering community and we have shown how this may be accomplished. Additionally, the engineer/modeller must communicate the binary nature of triggers so that appropriate factors of safety are built into the metrics and policy triggers. Determining if solutions are cost effective for benefits received by species is a question ultimately decided by resource managers and stakeholders. However, this methodology demonstrates that on a Pareto front, one can identify areas to get the most 'bang for the buck' in terms of habitat units. Results can serve as a guide to prioritizing projects and further analysis.

\section{References}

Adams, T.D., Cole, D.B., Miller, C.W., and Stauffer, N.E., 1992. GENRES a computer program system for reservoir operation with hydropower. Salt Lake City: Utah Division of Water Resources, $116 \mathrm{pp}$.

Addley, C., Neilson, B., Basdekas, L., and Hardy, T., 2005. Virgin River temperature model validation. Logan, Utah: Utah State University, 32.

Basdekas, L., 2007. Virgin River operations optimization model. Dissertation (PhD), 203 p. Utah State University.

Bishop, A.B., Hardy, T.B., and Glabou, B.D., 1990. Analyzing instream flow trade-offs for small hydropower development. Rivers, 1 (3), 137-182.

Boyle, 1998. Water supply needs for Washington and Kane counties \& lake Powell pipeline study. Boyle Engineering Corporation, $105 \mathrm{pp}$.

Boyle, 2003. Lake Powell pipeline feasibility study, feasibility study. Boyle Engineering Corporation, 362 pp.

Campbell, S.G., Hanna, R.B., Flug, M., and Scott, J.F., 2001. Modeling Klamath river system operations for quantity and quality. Journal of Water Resources Planning and Management, 127 (5), 284-294.

Cardwell, H., Jager, H.I., and Sale, M.J., 1996. Designing instream flows to satisfy fish and human water needs. Journal of Water Resources Planning and Management, 122 (5), 356-363.

Das, I. and Dennis, J.E., 1998. Normal-boundary intersection: a new method for generating the Pareto surface in nonlinear multicriteria optimization problems. SIAM Journal of Optimization, 8 (3), 631-657. 
Duan, Q., Sorooshain, S., and Gupta, V., 1992. Effective and efficient global optimization for conceptual rainfall-runoff models. Water Resources Research, 28 (4), 1015-1031.

Gupta, H.V., Sorooshain, S., and Yapo, P.O., 1998. Toward improved calibration of hydrologic models: multiple and noncommensurable measures of information. Water Resources Research, 34 (4), 751-763.

Neilson, B.T., 2006. Dynamic stream temperature modeling: understanding the causes and effects of temperature impairments and uncertainty in predictions. Logan: Utah State University.

Ritzel, B.J., Eheart, J.W., and Ranjithan, S., 1994. Using genetic algorithms to solve a multiple objective groundwater pollution containment problem. Water Resources Research, 30 (5), 1589-1603.

UDNR, 2002. Program document for the Virgin river resource management and recovery program. Salt Lake City: Utah Department of Natural Resources.
USDI, 1970. Fish and wildlife service. Federal Register, 35 (199), 16047.

USDI, 1989. Fish and wildlife service, endangered and threatened wildlife and plants; determination of endangered status for the Virgin river chub. Final rule. Federal Register, 54 (163), 35305-35311.

USDI, 2000. Fish and wildlife service, endangered and threatened wildlife and plants; designation of critical habitat for the Woundfin and Virgin River Chub. Final rule. Federal Register, 65 (17), 4141-4156.

USGS, 2003. Virgin river discharge at Virgin, UT. USGS Real time web page.

Ward, F.A. and Booker, J.F., 2003. Economic costs and benefits of instream flow protection for endangered species in an international basin. Journal of the American Water Resources Association, 39 (2), 427-440.

WCWCD, 2004. Information on the district. Available from: http://wcwcd.state.ut.us/ 